\title{
Organização e representação do conhecimento: um estudo aplicado aos documentos de gestão da qualidade
}

\author{
Knowledge management and representation: a study of \\ quality management documents
}

\section{Maria Aparecida Steinherz Hippert Ricardo Manfredi Naveiro}

Maria Aparecida Steinherz Hippert

Departamento de Construção Civil, Faculdade de Engenharia Universidade Federal de Juiz de

Rua José Lourenço Kelmer, $s / n$, Campus Universitário, Martelo Juiz de Fora - MG - Brasil CEP $36036-330$

Tel.: (32) 3229-3405 E-mail: aparecida.hippert@ufjf.edu.br

Ricardo Manfredi Naveiro COPPE, Programa de Engenharia de Produção Universidade Federal do Rio de Janeiro Rua Pedro Calmom, 550, Centro de Tecnologia, sala F-109 Cidade Universitária Caixa-Postal: 68507 Rio de Janeiro - RJ - Brasil CEP 21945-970 Tel.: (21) 2590-8817

E-mail: rnaveiro@poli.ufrj.br

Recebido em 11/04/09 Aceito em 27/06/09

\section{Resumo}

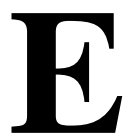

ste trabalho apresenta uma proposta de estrutura para organizar o conhecimento sobre materiais e serviços de construção utilizados por empresas de edificações. $\mathrm{O}$ trabalho tem início com uma revisão bibliográfica sobre a organização do conhecimento, utilizando o sistema de classificação facetado e as diretivas propostas pela norma ISO, para a classificação da informação na indústria da construção civil. Uma proposta de estrutura foi elaborada e aplicada na organização do conhecimento disponível no sistema de qualidade de uma pequena empresa construtora. A estrutura proposta pode ser considerada como uma estrutura genérica, que deverá ser adaptada por cada empresa interessada em aplicá-la. A ênfase do trabalho está na elaboração da estrutura segundo a classificação facetada, com o estabelecimento dos termos e conceitos relacionados a essa área do conhecimento. A proposta contribui para a reorganização e a otimização do conhecimento em construção civil, que se encontra disperso nas diversas áreas relacionadas à gestão da construção, sobretudo o conhecimento relativo aos materiais e serviços envolvidos no processo da construção.

Palavras-chave: Gestão da qualidade. Conhecimento. Classificação facetada.

\section{Abstract}

This paper proposes a structure for organizing knowledge on construction materials and services used by building companies. The paper begins with a review of the knowledge organization through the use of a faceted classification system, and the ISO standards directives for information classification in the construction industry. The proposed structure may be considered as generic, and must be adapted by a company that is interested in applying it. The paper emphasizes the creation of the structure according to the faceted classification by establishing terms and concepts related to this area of knowledge. The proposal contributes to reorganizing and optimizing knowledge in construction, which is scattered throughout several areas related to construction management, especially knowledge relevant to materials and services involved in the construction process.

Keywords: Quality management. Knowledge. Faceted classification. 


\section{Introdução}

O conhecimento tem sido considerado como fonte de vantagem competitiva (STEWART, 1998), bem como um fator impulsionador de uma nova economia - a economia do conhecimento (DRUCKER, 1993). Nessa nova economia, a competitividade da empresa de construção, de uma forma geral, está diretamente associada à criação e ao compartilhamento do conhecimento internamente e com os parceiros de negócios.

Para que o conhecimento possa ser utilizado, precisa estar organizado num formato que facilite essa utilização. Idealmente, o conhecimento de certa área ou domínio deve ser representado por uma ontologia, que pode ser entendida como um conjunto de conceitos padronizados, termos e definições aceitos por uma comunidade particular (CHANDRASEKARAN; JOSEPHSON; BENJAMINS, 1999). Vale ressaltar que não é tanto o vocabulário usado que qualifica o que é uma ontologia, mas as conceituações que os termos do vocabulário pretendem capturar (CHANDRASEKARAN; JOSEPHSON; BENJAMINS, 1999). Apesar de a ontologia ser a representação ideal do conhecimento de um domínio, ainda não existe uma ontologia pronta para a área de construção civil, o que motivou a realização de uma pesquisa sobre novas formas de estruturar o conhecimento.

Estruturar o conhecimento é organizá-lo segundo um critério de classificação, o que subentende um conjunto de propósitos. De forma simplista, a classificação é a ordenação de entidades em grupos ou classes com base em suas similaridades. O propósito de uma classificação é permitir a distinção dos termos em um conjunto, tornando-os únicos (BAILEY, 1994).

As primeiras dificuldades para se estruturar o conhecimento na construção civil são a falta de um sistema de classificação que seja de consenso no setor e a inexistência de uma norma nacional para a classificação e organização da informação neste setor.

A indústria da construção civil apresenta uma diversidade de produtos, serviços, equipamentos e tecnologias que, em função de suas características, apresentam linguagens técnicas específicas. Além disso, é comum encontrar diferenças regionais e setoriais de terminologias de produtos e serviços, conforme a região do país ou o local de uso. Essa situação dificulta o estabelecimento de padrões de referência que permitam a caracterização de modo único dos produtos e mesmo a identificação de seus similares (CDCON, 2003). O estabelecimento de padronização da terminologia e de codificação para a construção civil está entre as prioridades apontadas pela Associação Nacional de Tecnologia do Ambiente Construído (ANTAC) relacionadas às inovações do setor (ANTAC, 2002).

A padronização de termos pode servir para classificar o conhecimento a partir de uma terminologia aceita e inter-relacionada de produtos e serviços. Ao associar os processos de produção aos produtos, pode-se ordenar o conhecimento existente na empresa de forma a facilitar sua reutilização.

Com base no exposto, este trabalho tem por objetivo apresentar uma proposta de estrutura que organize, de forma integrada, o conhecimento sobre os materiais e serviços necessários ao processo construtivo utilizado pelas empresas de edificações. O foco do trabalho está na elaboração da estrutura em si, com o estabelecimento dos termos e conceitos necessários a ela. Cabe ressaltar que o conhecimento considerado restringe-se àquele descrito no escopo do sistema de gestão da qualidade, que se apresenta como a área mais bem documentada das pequenas empresas de edificações.

Estudos da natureza do aqui apresentado, direcionados à informação e ao conhecimento no setor de Arquitetura Engenharia e Construção (AEC), associados ou não ao uso dos recursos de tecnologia de informação, vêm sendo desenvolvidos continuamente no cenário nacional. Nesse sentido pode-se citar como exemplo o trabalho de Amorim e Peixoto (2006), que divulga o projeto CDCON: Classificação e terminologia para a construção. Já Amorim e Cheriaf (2007) apresentam um sistema de indexação e recuperação de informação na área de AEC, tendo por base o projeto CDCON e o ONTOARQ. Este último trata de um sistema para a criação de uma ontologia na área de AEC, também fazendo uso do vocabulário controlado do CDCON (RABELO; AMORIM, 2007). Finalmente, sob a óptica do desenvolvimento de software, pode-se citar o trabalho de Gonçalves et al. (2007), que apresenta a implementação em UML da informação de um projeto do setor de AEC, com a representação explícita das interfaces entre seus objetos.

\section{Fundamentação teórica}

As estruturas utilizadas pelos sistemas de classificação, em geral, baseiam-se em uma árvore hierárquica, que facilita o entendimento de sua lógica por parte dos usuários, mas cuja rigidez dificulta a inserção de novos elementos. Um 
problema dessas estruturas é que podemos encontrar objetos classificados em mais de uma classe, em função do enfoque considerado (CDCON, 2003). É o caso, por exemplo, dos metais sanitários, que não são classificados como metais (composição do material), mas são incluídos na classe acessórios de banheiro (função que desempenham), o que contradiz a condição apresentada de cada termo de pertencer a somente uma classe. Um exemplo de árvore hierárquica utilizada em sistema de orçamento por ser visto no TCPO 2000 (TCPO, 1999) e nas Práticas SEAP, vigentes na administração pública federal (SECRETARIA..., 2001).

Outra opção para classificação do conhecimento é a utilização de facetas, conjunto de características aplicáveis ao universo que está sendo analisado. A classificação facetada foi desenvolvida por Ranganathan (1967) para sistematização dos termos das áreas de conhecimento, com o objetivo de criar bibliotecas. As diferentes partes de um assunto podem ser vistas como um todo e estar contidas em cinco categorias fundamentais: personalidade, matéria, energia, espaço e tempo (CDCON, 2003).

A classificação facetada é um "[ . . . ] sistema que agrupa termos estruturados, na base da análise de um assunto, para identificação de suas facetas, isto é, dos diferentes aspectos nele contidos [ . . . '”. As facetas podem ser definidas como "[ . . . ] um conjunto de termos produzidos pela ampla aplicação de um princípio de divisão[ . . . ]" (BARBOSA, 1972) ou "[ . . . ] um conjunto exaustivo de propriedades de qualidades semelhantes [... ]" (CDCON, 2003).

As facetas "desdobram" o assunto em categorias fundamentais, e essas divisões formam a espinha dorsal da estrutura de classificação. Os termos são dispostos nas diferentes classes, sendo cada classe um conjunto formado por termos definidos por propriedades relevantes para a classificação. As propriedades que determinam as classes são ordenadas por uma crescente especificação do geral para o particular. Aquelas presentes em um patamar superior são gerais, enquanto as presentes em patamares inferiores são específicas (CDCON, 2003). A associação matricial entre os elementos de cada faceta resulta na descrição do objeto do universo em estudo, não sendo necessária a utilização de todas as facetas.

Embora este trabalho tenha usado o CDCON (2003) como referência, outros trabalhos discutem a utilização da classificação facetada, como, por exemplo, Tristão et al. (2004), num estudo sobre classificação da informação sobre cerâmica para revestimento.
A utilização de facetas está mais próxima dos modelos de classificação da informação da construção, presentes na norma ISO/DIS 12006-2 - Organization of information about construction works - Part 2: Framework for classification of information (ISO, 1998), que apresenta uma estrutura relacional para a informação da construção. A partir de um modelo básico do processo construtivo, a norma ISO/DIS identifica três classes de objetos, segundo sua função no processo de produção: recursos ou entradas, processos e resultados ou saídas.

\section{Metodologia de pesquisa}

O desenvolvimento da estrutura para organização do conhecimento partiu de uma revisão bibliográfica, seguida de uma pesquisa de campo junto a uma pequena empresa de edificações com sistema de qualidade implantado. Foram realizadas as seguintes etapas:

(a) definição da abrangência da análise: inicialmente foram definidas as facetas necessárias para a classificação pretendida para os materiais de construção e serviços, a partir do conceito de processo apresentado na ISO DIS 12006-2 (ISO, 1998): recursos, processos e resultados;

(b) finalidade da organização pretendida: no presente trabalho busca-se responder às questões referentes aos materiais e serviços utilizados pela empresa em suas obras: características, normas atendidas, aquisição, recebimento e armazenamento (para os materiais);

(c) resgate do conhecimento existente nos documentos do sistema de qualidade da empresa construtora: escolha de uma pequena empresa que possuía um sistema de gestão da qualidade implantado e disponibilizou o acesso a seus documentos. As informações foram obtidas através da leitura dos documentos da qualidade e da realização de entrevistas junto ao responsável pelo sistema de qualidade na empresa;

(d) montagem da estrutura para organização do conhecimento: definidas as facetas e analisados os documentos da qualidade, foram elaboradas as tabelas de classificação para documentos, processos (de execução e gerenciais), materiais e elementos da construção;

(e) estabelecimento dos termos e conceitos: na elaboração de todas as tabelas anteriores foi necessária a utilização de termos e conceitos. Tomando por base os processos de execução, que são aqueles necessários para a obtenção dos elementos da construção, foram relacionados e analisados os conceitos, encontrados na 
bibliografia, para a árvore de elementos. A partir desta, foram estabelecidos os termos das demais tabelas;

(f) teste da estrutura: com o intuito de verificar a pertinência da árvore, bem como dos termos e conceitos propostos, foi realizado um teste com três profissionais atuantes no mercado mediante a aplicação de um questionário. O questionário contemplava a árvore elementos da construção composta dos elementos infraestrutura, supraestrutura, vedação vertical, abertura, instalação, impermeabilização, cobertura e revestimento, envolvendo perguntas sobre 67 termos distribuídos em 13 páginas. Ao final de cada termo e conceito, foram inseridas linhas em branco, de modo que o entrevistado pudesse manifestar seu próprio termo e/ou conceito, caso não concordasse com os que lhe foram apresentados. Um trecho do questionário, para o elemento de abertura porta, pode ser visualizado no Quadro 1. O questionário foi enviado ao primeiro respondente por correio eletrônico sem as referências dos termos e conceitos, porque a presença delas poderia sugerir uma resposta, tendo em vista o peso dado pelo proponente à origem da informação. Foi solicitado que se fizesse uma análise dos termos e conceitos propostos e que se indicasse, para os termos apresentados, os conceitos que no seu entendimento melhor atendiam aos termos propostos. Como o profissional praticamente fez suas escolhas dentro das opções apresentadas, com poucas inserções ou comentários, mudou-se a forma de abordagem. O questionário passou a ser respondido na presença do pesquisador, tendo o respondente liberdade para inserção de comentários; e

(g) representação do conhecimento: para a representação da estrutura foram adotados os seguintes critérios: representação baseada em processo; visão sistêmica de todo o processo através de uma representação gráfica e descritiva; e utilização de uma ferramenta de representação de fácil utilização. A partir desses critérios foi selecionada uma ferramenta para a representação gráfica, bem como elaborada uma planilha (ROMANO, 2003) contendo os documentos necessários para a execução dos processos e os documentos referentes aos produtos gerados.

\section{Desenvolvimento da estrutura}

\section{Definição da abrangência da análise}

Partindo da ISO DIS 12006-2 (ISO, 1998) foram definidas as facetas necessárias para a classificação pretendida. Na classe recursos dessa norma foram adotadas as facetas documentos e atributos. A primeira considera os documentos exigidos pelo sistema de qualidade. Nesse caso, dizem respeito tanto aos materiais quanto aos processos de execução e gestão. Na segunda faceta os materiais são identificados pelos atributos que os qualificam, no caso, o material básico de que são constituídos. Esta faceta agrupa os objetos segundo suas características físicas. Um exemplo de composição de atributos utilizados na especificação de um material de construção é apresentado no trabalho de Santos (2004).

Para a classe processos da ISO DIS 12006-2 (1998) são considerados os processos de execução e processos gerenciais. Este último considera os processos diretamente relacionados à gestão da qualidade, que se referem à aquisição de materiais, incluindo aí a qualificação de fornecedores. Finalmente, para a classe resultados da ISO utilizou-se a faceta elementos da construção, conforme adotado pelo CDCON (2003). As facetas consideradas estão no Quadro 2.

\section{1) Porta (SCHIMDT, 2000 apud CDCON, 2003):}

A) abertura na parede (externa e interna) de uma edificação para comunicação entre o ambiente externo e ambientes internos (SCHIMDT, 2000 apud CDCON, 2003);

B) caixilho que, entre outras finalidades, permite ou impede o acesso de um recinto para outro segundo NBR 10820 (ASSOCIAÇÃO BRASILEIRA DE NORMAS TÉCNICAS, 1989);

C) conjunto funcional composto de marco, alizar, ferragens e uma ou mais folhas, cuja função é regular a abertura ou fechamento de um vão transitável, segundo a NBR 8037 (ASSOCIAÇÃO BRASILEIRA DE NORMAS TÉCNICAS, 1983);

D) abertura feita nas paredes, nos muros ou em painéis envidraçados, rasgada até ao nível do pavimento, que serve de vedação ou acesso a uma ambiente (www.cefet-se.com, www.ecivilnet.com);

E) conjunto funcional composto de batente, alizar e folha (YAZIGI, 1998).

Quadro 1 - Estrutura elementos da construção - exemplo 


\begin{tabular}{|l|l|l|l|}
\hline \multicolumn{2}{|c|}{ ISO DIS 12006-2 (ISO, 1998) } & \multicolumn{2}{c|}{ Proposta } \\
\hline FACETA & Valoração & FACETA & Valoração \\
\hline \multirow{3}{*}{ Recursos } & Recursos de informação & Documento & $\begin{array}{l}\text { Especificação } \\
\text { Norma técnica }\end{array}$ \\
\cline { 2 - 4 } & Produtos para a construção & Atributo & Material básico \\
\hline \multirow{4}{*}{ Processos } & Métodos de trabalho & Documento & Instrução de trabalho \\
\cline { 2 - 4 } & & Processo & Execução \\
\cline { 2 - 4 } & & Documento & $\begin{array}{l}\text { Aquisição } \\
\text { Qualificação e gestão }\end{array}$ \\
\cline { 3 - 4 } & & Processo & Gerencial \\
\hline Resultados & Elemecedor \\
\hline
\end{tabular}

Quadro 2 - Relação entre as facetas da ISO DIS 12006-2 e desta proposta

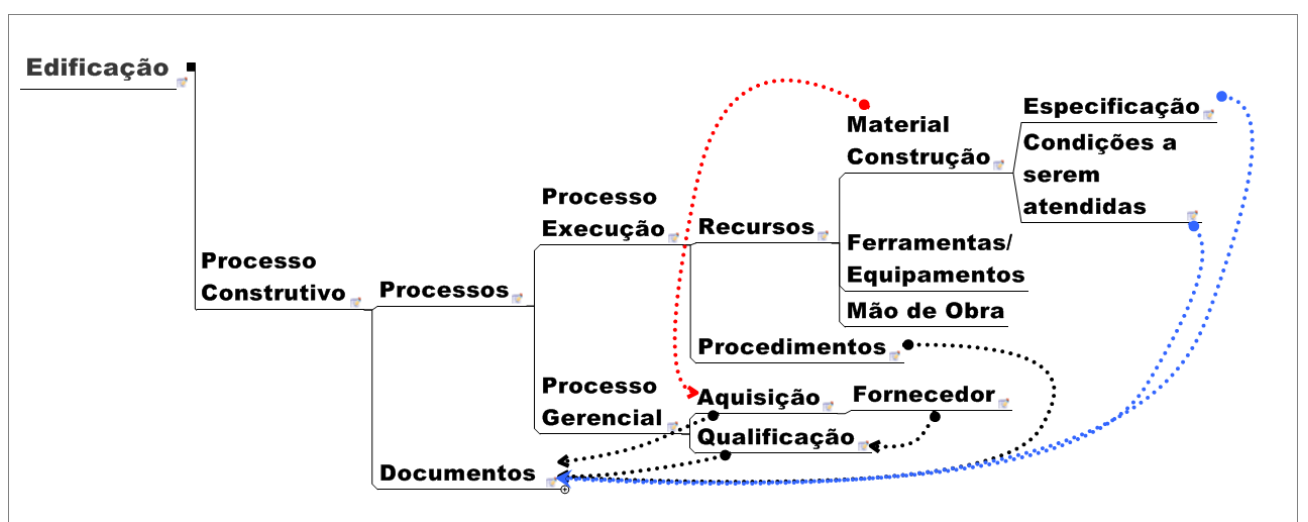

Figura 1 - Relacionamento entre as categorias presentes no processo construtivo

\section{Finalidade da organização}

As questões anteriormente formuladas sobre os materiais e serviços utilizados pela empresa em suas obras devem existir de forma explícita nos documentos de gestão da qualidade (recorte adotado no presente trabalho) da empresa estudada. Esse conhecimento diz respeito aos serviços, materiais de construção e fornecedores (termos normalmente utilizados na empresa).

Os serviços correspondem aos processos de execução que são realizados, seguindo procedimentos, e utilizam materiais de construção (insumos), ferramentas e equipamentos e mão de obra de execução. Os materiais de construção, necessários à realização dos serviços, possuem uma especificação, são adquiridos de fornecedores e devem atender ao disposto no processo de aquisição. Os fornecedores, por sua vez, devem atender às exigências dispostas no processo de qualificação de fornecedores. O relacionamento entre essas categorias está disposto na Figura 1.

\section{Resgate do conhecimento existente nos documentos do sistema de qualidade da empresa construtora}

A empresa escolhida para o estudo de campo é de pequeno porte, com uma pequena base técnica. Atua regionalmente e, na maior parte das vezes, na realização de obras residenciais uni e multifamiliares.

Ao implantar o sistema de qualidade, a empresa preparou uma lista de serviços de execução controlados que têm grande impacto na qualidade do produto. Para esses serviços controlados foram elaboradas as instruções de trabalho, que descrevem o processo a ser seguido para a execução dos serviços.

A partir da lista de serviços controlados, a empresa elaborou uma lista de materiais considerados como de grande impacto na qualidade tanto dos serviços quanto do produto final, o edifício. Para esses materiais foram elaboradas as especificações de materiais (referenciadas às Normas Técnicas), os critérios de inspeção e ensaios de recebimento e manuseio, além dos critérios de armazenagem, embalagem, preservação e entrega. Estes são procedimentos recomendados para todos os materiais utilizados pela empresa, sendo obrigatórios para os materiais controlados.

Quanto aos processos de gestão, para o caso dessa empresa, foram elaborados o processo de aquisição (que considera os dados para aquisição, coleta de preços e confirmação da aquisição), bem como os procedimentos de verificação do produto e os procedimentos de qualificação de fornecedores (seleção e avaliação), estabelecendo os níveis de qualificação para eles. 


\section{Montagem da estrutura para a organização do conhecimento}

A primeira tabela estruturada foi a de documentos. Partindo da relação de documentos criados pela empresa, analisou-se a classificação proposta pelo CDCON (2003) e chegou-se à classificação adotada para os documentos.

A seguir, passou-se a estudar as tabelas de processos. Para a montagem da tabela de processos de execução foi realizada uma busca na literatura, de forma a verificar como esses serviços se encontram organizados. Foram usadas, para comparação, as tabelas do CDCON (2003), Práticas SEAP (2001) e TCPO 2000 (1999), apesar de as duas últimas utilizarem uma classificação hierárquica. As tabelas do $\mathrm{CDCON}$ foram selecionadas por apresentarem uma classificação por facetas, como a utilizada neste trabalho. As Práticas SEAP foram selecionadas por serem adotadas pelo Governo Federal na realização de obras públicas, e o TCPO, por apresentar uma estrutura muito difundida (através de suas composições de preços unitárias - CPU) para a realização de orçamentos.

Um exemplo da comparação entre a classificação dos serviços nessas tabelas é apresentado no Quadro 3. Uma análise desse quadro permite que sejam feitas as seguintes considerações:

(a) alguns serviços aparecem classificados de forma muito parecida, como, por exemplo, locação de obra, compactação e aterro. Esta é a forma adotada neste trabalho;

(b) a fundação está classificada, também, de forma muito próxima, com a exceção do TCPO, que apresenta uma classificação por material. Formas, armadura, concreto usados para a fundação estão no item Concreto. Neste trabalho optou-se por manter a classificação pelo critério da função do serviço, visto que o serviço tem uma função básica, mas pode ser realizado com vários tipos de materiais;

(c) a estrutura de concreto aparece no SEAP, no primeiro nível, com os elementos estruturais básicos, pilar, viga e laje, para depois subdividir em forma, armação e concreto. O TCPO mantém a classificação por material. Este trabalho mantém a classificação por função no primeiro nível e, a seguir, se subdivide nos elementos básicos; e

(d) as alvenarias, tanto estruturais quanto de vedação, aparecem agrupadas nas classificações SEAP e TCPO. Este trabalho mantém a classificação por função e daí insere a alvenaria estrutural na classe supraestrutura e alvenaria não estrutural na de vedação.

Após a classificação dos processos de execução, têm-se ainda, dentro da classe de processos, os processos gerenciais. Dentro destes, são considerados no presente trabalho os processos de aquisição e de qualificação de fornecedores. Estes processos são adotados pela empresa para todos os materiais e serviços controlados. Segundo o PMI (PROJECT..., 2000), os processos gerenciais devem considerar os processos de iniciação, planejamento, execução, controle e encerramento. Portanto, a tabela de processos gerenciais compreende os processos de planejamento, execução e controle que são realizados entre o início e o encerramento dos processos gerenciais de aquisição e qualificação de fornecedores.

Com as tabelas de documentos, processos de execução e processos gerenciais elaboradas, passou-se à tabela de materiais. Os materiais de construção são classificados pelo material básico que os constitui. Para os materiais controlados da empresa considerada, a associação é direta do material de construção com o material básico.

Por fim, foi elaborada a árvore de elementos da construção, considerando, conforme já exposto, que estes são constituídos por materiais aplicados segundo um processo de execução a um sistema ou entidade construída. Inicialmente, essa tabela foi montada a partir dos processos de execução.

\section{Estabelecimento de termos e conceitos}

$\mathrm{Na}$ elaboração de todas as tabelas anteriores foi necessária a utilização de conceitos e termos. Conceito e termo são definidos respectivamente como unidade e sua designação no contexto do sistema de conceitos (CAMPOS, 2001). O estabelecimento de uma linguagem comum pode contribuir para a reconciliação entre os diversos agentes envolvidos no processo construtivo. 


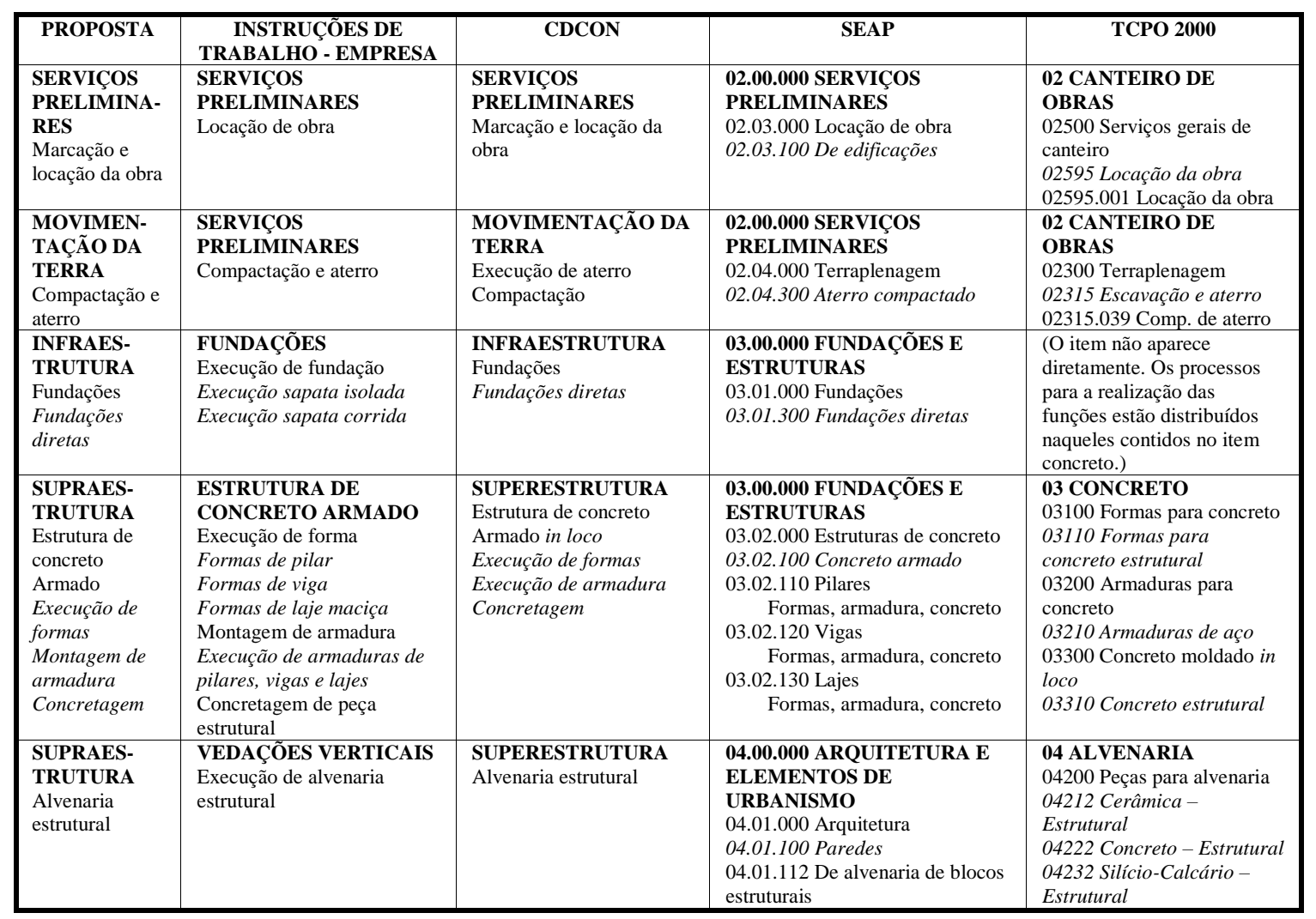

Quadro 3 - Proposta de Classificação para Processos de Execução - extrato

\section{EDIFICAÇÃO}

Produto constituído por conjunto de elementos definidos e $\quad$ ABNT, 1995, NBR 13531 Elaboração de projetos de articulados em conformidade com os principais e as técnicas edificações - Atividades técnicas - Procedimento. 10 p. da arquitetura e da engenharia para, ao integrar a urbanização, desempenhar determinadas funções ambientais em níveis adequados. Ex.: casa Ambiente construído constituído de uma ou mais unidades autônomas e partes de uso comum.

ABNT, 1998, NBR 14037 Manual de operação, uso e manutenção das edificações - Conteúdo e recomendações para elaboração e apresentação. 5 p.

Quadro 4 - Exemplos de conceitos apresentados em normas da ABNT com mesmo significado

\section{SAPATA}

Elemento de fundação superficial de concreto armado dimensionado, ABNT, 1996, NBR 6122 Projeto e execução de de modo que as tensões de tração nele produzidas não sejam resistidas pelo concreto, mas sim pelo emprego da armadura. Pode possuir espessura constante ou variável, sendo sua base em planta normalmente quadrada, retangular ou trapezoidal.

Componentes fixados no painel da grade móvel, que serve para deslizamento e apoio nas peças fixas. fundações. $33 \mathrm{p}$.

\section{Quadro 5 - Exemplos de termos usados em normas da ABNT com significados diferentes}

A proposta inicial era a de se trabalhar com os termos e conceitos contidos no CDCON. Entretanto, vários dos termos necessários à montagem da estrutura ainda não haviam sido avaliados pelos especialistas. Além disso, o CDCON (2003) apresenta uma série de conceitos extraídos das normas ABNT. Essas normas, por sua vez, apresentam várias distorções em relação aos termos nelas contidos. A mais comum das distorções é constar em várias normas o mesmo termo, com o mesmo sentido, com conceitos escritos de forma diferente (Quadro 4). Outras vezes, há casos em que são utilizados termos homônimos para conceitos diferentes (Quadro 5). Ainda há termos em que ocorrem os dois casos citados acima: o termo se repete em várias normas, algumas vezes com os conceitos apenas redigidos 
de forma diferente, outras vezes, com outro sentido (Quadro 6).

Embora não seja objetivo deste trabalho o estabelecimento de uma terminologia para a área da construção, foi necessário o estabelecimento de um conjunto de termos e conceitos que permitissem a elaboração de uma estrutura consistente para a classificação do conhecimento pretendido.

Tomando por base os processos de execução, que são aqueles necessários para a obtenção dos elementos da construção, os conceitos foram estudados para a árvore de elementos.

A partir da árvore de elementos já elaborada foram relacionados os termos correspondentes encontrados no CDCON, em normas da ABNT, em dicionários da construção disponíveis na web e na bibliografia consultada, o que resultou em listagens com uma diversidade de termos e conceitos. Em vista disso, foi necessário realizar um teste que avaliasse tanto a tabela de elementos quanto os termos e conceitos nela utilizados. $\mathrm{O}$ teste realizado está descrito no item Teste da estrutura.

Da árvore de elementos foram gerados os termos para os processos de execução. Para a árvore de material básico e documentos, a escolha dos termos mais condizentes ficou a cargo do primeiro autor deste trabalho. Um exemplo completo da estrutura proposta pode ser verificado em Cintra (2005).

Cabe ressaltar que não se pretendeu desenvolver toda a árvore para as facetas utilizadas, mas somente a parte necessária para demonstrar que o conhecimento existente nos documentos da qualidade da empresa estudada podia nela ser ancorado.

\section{Teste da estrutura}

O teste da estrutura foi realizado com três profissionais atuantes no mercado da construção civil da cidade. $\mathrm{O}$ primeiro está formado há 10 anos e atua em canteiros de obras. $\mathrm{O}$ segundo tem mais de 30 anos de formado, com experiência em cálculo estrutural e acompanhamento de obras. $\mathrm{O}$ terceiro tem graduação há 25 anos, com atuação em cálculo estrutural e execução de obras.

O primeiro profissional enviou suas respostas por correio eletrônico. Passando à abordagem presencial, foram gastas cinco horas de discussão com o segundo profissional e seis horas com o terceiro. A mudança da forma de abordagem gerou uma maior riqueza de resultados, com uma análise mais aprofundada do conteúdo apresentado. As discussões serviram para testar a estrutura na medida em que foram analisados não somente termos e conceitos, mas também a pertinência ou não da árvore apresentada.

Um trecho dos resultados obtidos pode ser visualizado no Quadro 7. Enquanto o profissional 1 optou pelo conceito da norma, para o profissional 2 "porta" se refere à folha (de porta). $\mathrm{O}$ profissional 3 preferiu elaborar um novo conceito, em que não especifica os componentes constituintes da porta.

Ainda dentro dos elementos de abertura, foram analisados os termos janela, guarnição, batente, marco, alizar e folha. Porta e janela formam, de imediato, duas classes. A guarnição, composta de marco (ou batente) e alizar, pode se referir tanto à porta quanto à janela e, por isso, forma uma nova classe. Do mesmo modo, a folha, que pode se referir tanto à folha de porta quanto à folha de janela, deve ser considerada numa classe em separado.

Os elementos de abertura, considerados na árvore de elementos da construção, estão representados no Quadro 8. O teste realizado permitiu que fossem feitos ajustes na tabela apresentada aos profissionais. Um exemplo dessa mudança foi a criação das classes guarnição e folha nos elementos de abertura, mostrados acima.

\begin{tabular}{|l|l|}
\hline \multicolumn{2}{|c|}{ ELEMENTO } \\
\hline $\begin{array}{l}\text { Parte elementar da obra, constituída por } \\
\text { material natural ou de fabricação industrial. }\end{array}$ & $\begin{array}{l}\text { ABNT, 1985, NBR 8798: Execução e controle de obras em alvenaria } \\
\text { estrutural de blocos vazados de concreto. 15 p. }\end{array}$ \\
\hline $\begin{array}{l}\text { Termo relacionado à protensão - Peça a ser } \\
\text { protentida. }\end{array}$ & $\begin{array}{l}\text { ABNT, 1989, NBR 10839: Execução de obras de arte especiais em } \\
\text { concreto armado e concreto protendido. 40 p. }\end{array}$ \\
$\begin{array}{l}\text { Parte da obra suficientemente elaborada, } \\
\text { constituída da reunião de um ou mais } \\
\text { componentes. }\end{array}$ & $\begin{array}{l}\text { ABNT, 1989, NBR 10837: NB-1228 Cálculo de alvenaria estrutural de } \\
\text { blocos vazados de concreto. 20 p. }\end{array}$ \\
\hline
\end{tabular}

Quadro 6 - Exemplos de termos usados em normas da ABNT para conceitos com mesmo significado ou não 


\begin{tabular}{|c|c|}
\hline 6.1 & Porta (SCHIMDT, 2000 apud CDCON, 2003) \\
\hline A & $\begin{array}{l}\text { Abertura na parede (externa e interna) de uma edificação para comunicação entre o ambiente externo e } \\
\text { ambientes internos (SCHIMDT, 2000 apud CDCON, 2003) }\end{array}$ \\
\hline B & $\begin{array}{l}\text { Caixilho que, entre outras finalidades, permite ou impede o acesso de um recinto para outro segundo } \\
\text { NBR } 10820 \text { (ABNT, 1989) }\end{array}$ \\
\hline $\mathrm{C}$ & $\begin{array}{l}\text { Conjunto funcional composto de marco, alizar, ferragens e uma ou mais folhas, cuja função é regular a } \\
\text { abertura ou o fechamento de um vão transitável segundo NBR } 8037 \text { (ABNT, 1983) }\end{array}$ \\
\hline $\mathrm{D}$ & $\begin{array}{l}\text { Abertura feita nas paredes, nos muros ou em painéis envidraçados, rasgada até ao nível do pavimento, } \\
\text { que serve de vedação ou acesso a uma ambiente (www.cefet-se.com, www.ecivilnet.com) }\end{array}$ \\
\hline \multirow[t]{4}{*}{$\mathrm{E}$} & Conjunto funcional composto de batente, alizar e folha (YAZIGI, 1998) \\
\hline & Profissional 1: Conceito C \\
\hline & Profissional 2: A folha \\
\hline & $\begin{array}{l}\text { Profissional 3: "Abertura na parede (externa e interna) de uma edificação para comunicação entre os } \\
\text { ambientes, dotada de componentes que permitam seu fechamento quando desejado." }\end{array}$ \\
\hline
\end{tabular}

Quadro 7 - Estrutura elementos da construção: resultados parciais

\begin{tabular}{|c|c|}
\hline 6 & ELEMENTOS DE ABERTURA \\
\hline & Elementos utilizados para guarnecer vãos de paredes \\
\hline \multirow[t]{2}{*}{6.1} & Porta \\
\hline & $\begin{array}{l}\text { Abertura na parede (externa e interna) de uma edificação para comunicação entre os } \\
\text { ambientes, dotada de componentes que permitam seu fechamento quando desejado. }\end{array}$ \\
\hline \multirow[t]{2}{*}{6.2} & Janela \\
\hline & $\begin{array}{l}\text { Abertura na parede externa de uma edificação para iluminação e ventilação do interior cujo } \\
\text { limite inferior está acima do nível do piso, permitindo a penetração lateral da luz, visão ao } \\
\text { exterior e ventilação natural. }\end{array}$ \\
\hline \multirow[t]{2}{*}{6.3} & Guarnição \\
\hline & Conjunto de marco (ou batente) com alizar. \\
\hline \multirow[t]{2}{*}{$\mathbf{A}$} & Batente \\
\hline & $\begin{array}{l}\text { Elemento fixo que guarnece o vão da parede onde se prende a folha de porta ou janela e } \\
\text { que tem um rebaixo contra o qual a folha se fecha. }\end{array}$ \\
\hline \multirow[t]{2}{*}{ B } & Marco \\
\hline & $\begin{array}{l}\text { Elemento fixo constituído por ombreiras e travessa, destinado a guarnecer o vão e a } \\
\text { sustentar a folha de porta e janela. O marco também é designado por diversos outros } \\
\text { termos, tais como aduela, aro, batente, caixão, caixilho, couceira e portal. }\end{array}$ \\
\hline \multirow[t]{2}{*}{$\mathbf{C}$} & Alizar \\
\hline & Peça fixada ao batente e destinada a acabamentos e mata-juntas. \\
\hline \multirow[t]{2}{*}{6.4} & Folha \\
\hline & Painel móvel ou fixo de uma porta ou de uma janela. \\
\hline \multirow[t]{2}{*}{$\mathbf{A}$} & Folha de porta \\
\hline & Painel fixo ou móvel de uma porta \\
\hline \multirow[t]{2}{*}{$\mathbf{s} / \mathbf{n}$} & Esquadria \\
\hline & $\begin{array}{l}\text { Qualquer tipo de caixilho usado na obra, como portas, janelas, etc. Conjunto formado por } \\
\text { dobradiças, fechos, braços de alavancas (ferragens). }\end{array}$ \\
\hline \multirow[t]{2}{*}{$\mathbf{s} / \mathbf{n}$} & Caixilho \\
\hline & Parte da esquadria que sustenta e guarnece os vidros de portas e janelas \\
\hline
\end{tabular}

Quadro 8 - Tabela elementos: conceitos parciais

Com o teste, não se teve a intenção de fazer que os profissionais mudassem os conceitos que possuem sobre os termos analisados. Esses conceitos foram assimilados ao longo de suas experiências profissionais. Conforme expresso pelo profissional 2, vários dos termos utilizados por ele (principalmente na área de estruturas) vêm dos softwares (por exemplo, de cálculo estrutural) que ele utiliza no seu dia a dia.

\section{Representação do conhecimento}

\section{Representação gráfica}

Após a realização de pesquisas com algumas ferramentas para a representação gráfica da estrutura, optou-se pelo software MindManager: Software for Visualizing and Managing Information, visto que ele atendia aos critérios estabelecidos.

O diagrama gerado pelo software permite uma visualização geral do processo que está sendo representado, bem como a associação de documentos aos termos utilizados no diagrama. A 
versão mais recente do software permite ainda sua integração com outros, tais como editores de texto e softwares de apresentação.

Como exemplo de aplicação do MindManager, têm-se a Figura 1, para o caso geral, e a Figura 2, para o caso porta.

A partir da representação gráfica apresentada na Figura 2, pode-se extrair que a porta de madeira:

(a) deve atender ao disposto na norma NBR 8037 (ABNT, 1983) - Porta de madeira de edificação;

(b) deve ser instalada segundo o processo de execução de esquadrias disposto nas instruções de trabalho (colocação de batentes e portas);

(c) deve ser adquirida segundo um processo de aquisição praticado pela empresa e que atende às recomendações dispostas no documento de mesmo nome. Interage com fornecedores, os quais devem ser qualificados segundo o processo de qualificação de fornecedores também disposto em documento;

(d) a porta e a guarnição são adquiridas segundo as especificações descritas para o produto - porta de madeira e guarnição de madeira - e deve atender ao disposto nos critérios de inspeção e recebimento, bem como nos critérios de manuseio e armanezamento; e

(e) após recebidas a porta e a guarnição, é gerada a ficha de recebimento de material, em que se verifica a conformidade delas. Depois de realizada a instalação, deve-se preencher uma ficha de inspeção de serviço, que documenta o serviço realizado e pode apontar ou não uma não conformidade. Caso se verifique essa ocorrência, deverão ser tomadas as providências para corrigila.

\section{Tabela insumo, processo e produto}

Junto à representação gráfica da estrutura para organização do conhecimento foi elaborada uma planilha contendo os documentos sobre os materiais, sobre a execução dos processos, bem como os documentos referentes aos produtos gerados.

As dimensões consideradas na planilha seguem o disposto no modelo de processo da ISO (1998) e compreendem recurso, processo e resultado. A planilha assim elaborada permite que sejam identificadas as relações entre os materiais e serviços utilizados no processo construtivo e o resultado alcançado. Em função dos documentos da qualidade acessados, a planilha considera somente os documentos referentes aos materiais e aos processos de execução. Exclui os processos gerenciais de aquisição e qualificação (visto que eles dizem respeito a todos os materiais controlados; a empresa utiliza um único documento para o processo de aquisição e outro para a qualificação), bem como os documentos referentes aos resultados obtidos - elementos da construção que não foram disponibilizados (como, por exemplo, as fichas de recebimento de material e de inspeção de serviços). A representação descritiva da estrutura para organização do conhecimento está no Quadro 9.

O Quadro 10 representa uma simplificação da Figura 2 e nele são apresentadas somente as especificações dos materiais (porta e guarnição) e a instrução de trabalho (colocação de batentes e portas) a ser seguida no processo de execução (colocação de porta) para a obtenção do elemento de abertura porta.

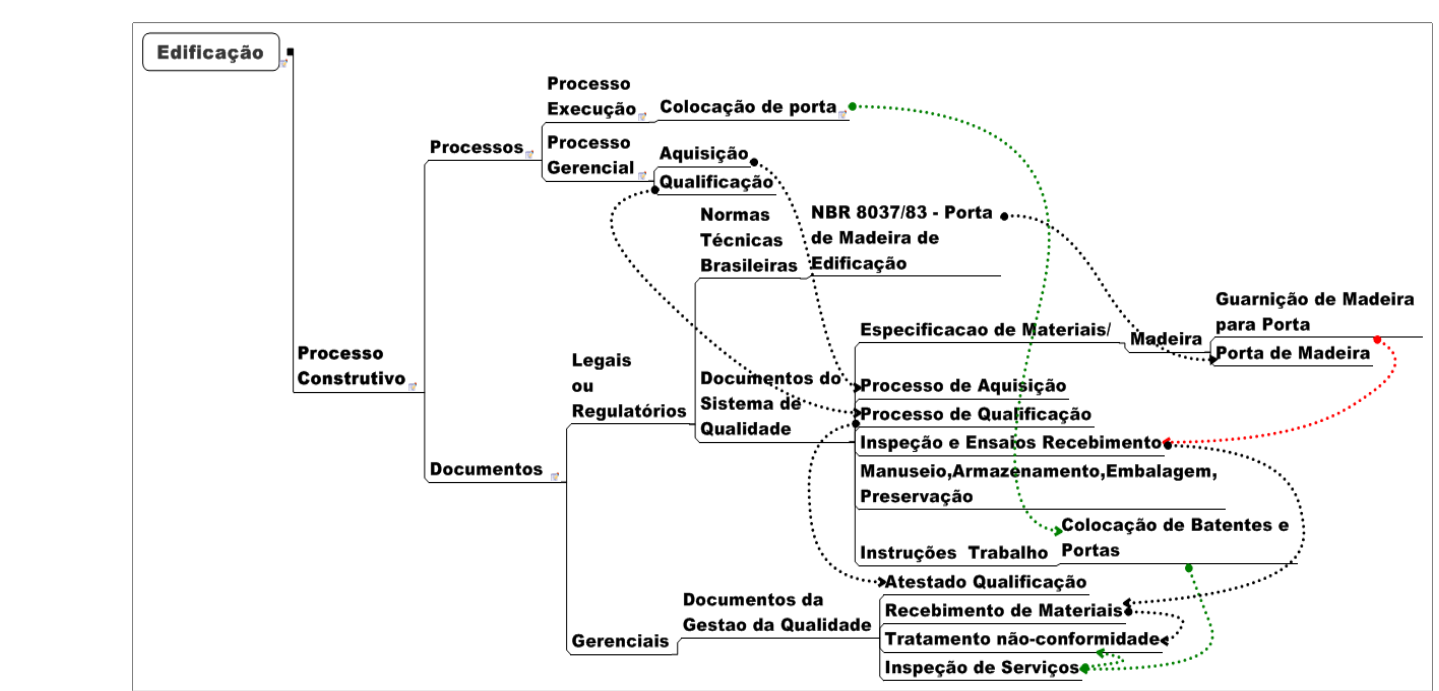

Figura 2 - Exemplo de aplicação da estrutura: caso porta 


\begin{tabular}{|l|l|l|l|l|}
\hline \multicolumn{2}{|c|}{ Recurso } & \multicolumn{2}{c|}{ Processo } & \multicolumn{1}{c|}{ Resultado } \\
\hline $\begin{array}{l}\text { Faceta } \\
\text { Documento }\end{array}$ & $\begin{array}{c}\text { Faceta } \\
\text { Atributo }\end{array}$ & $\begin{array}{c}\text { Faceta } \\
\text { Documento }\end{array}$ & $\begin{array}{c}\text { Faceta } \\
\text { Processo }\end{array}$ & $\begin{array}{c}\text { Faceta } \\
\text { Elementos }\end{array}$ \\
\hline $\begin{array}{l}\text { Especificação } \\
\text { Material }\end{array}$ & $\begin{array}{l}\text { Material } \\
\text { Básico }\end{array}$ & $\begin{array}{l}\text { Instrução de } \\
\text { Trabalho }\end{array}$ & $\begin{array}{l}\text { Processo de } \\
\text { Execução }\end{array}$ & $\begin{array}{l}\text { Elementos da } \\
\text { Construção }\end{array}$ \\
\cline { 1 - 1 } Norma técnica & & & & \\
\hline
\end{tabular}

Quadro 9 - Facetas e documentos considerados

\begin{tabular}{|c|c|c|c|c|}
\hline \multicolumn{2}{|c|}{ Recurso } & \multicolumn{2}{|c|}{ Processo } & \multirow{2}{*}{$\begin{array}{c}\text { Resultado } \\
\text { Faceta } \\
\text { Elementos }\end{array}$} \\
\hline $\begin{array}{l}\text { Faceta } \\
\text { Documento }\end{array}$ & $\begin{array}{c}\text { Faceta } \\
\text { Atributo }\end{array}$ & $\begin{array}{c}\text { Faceta } \\
\text { Documento }\end{array}$ & $\begin{array}{c}\text { Faceta } \\
\text { Processo }\end{array}$ & \\
\hline Porta de Madeira & Madeira & $\begin{array}{l}\text { ESQUADRIAS } \\
\text { Colocação de Janela } \\
\text { Caixilhos/janelas alum. } \\
\text { Contramarco/janela } \\
\text { mad. }\end{array}$ & $\begin{array}{l}\text { ESQUADRIAS } \\
\text { Colocação de } \\
\text { janela } \\
\text { Colocação de porta }\end{array}$ & $\begin{array}{l}\text { ELEMENTOS DE } \\
\text { ABERTURA } \\
\text { Porta } \\
\text { Janela }\end{array}$ \\
\hline $\begin{array}{l}\text { NBR 8037:1983 } \\
\text { Porta de madeira } \\
\text { de edificação }\end{array}$ & & $\begin{array}{l}\text { Colocação de batentes e } \\
\text { portas } \\
\text { Batentes de madeira } \\
\text { Colocação das portas }\end{array}$ & & $\begin{array}{l}\text { Guarnição } \\
\text { Alizar }\end{array}$ \\
\hline $\begin{array}{l}\text { Guarnição de } \\
\text { madeira maciça }\end{array}$ & & & & \\
\hline Não existe norma & & & & \\
\hline
\end{tabular}

Quadro 10 - Exemplo de aplicação da tabela: caso porta

Como exemplo da faceta elementos presente na coluna Resultado do Quadro 9 têm-se os elementos de abertura, apresentados no Quadro 8, com os conceitos definidos para os mesmos. Um exemplo de aplicação da tabela para o caso porta é apresentado no Quadro 10

A essa estrutura poderia ser ainda inserido o conhecimento existente em outros documentos da empresa, como, por exemplo, contratos, pedidos de compra, controle de materiais, etc., que são gerados para as obras que a empresa realiza. Entretanto, essa situação foge ao escopo deste trabalho na medida em que exigiria o estudo de caso de uma empresa com o levantamento do conhecimento referente a suas obras.

Finalmente, pode-se afirmar que a estrutura proposta para a organização do conhecimento, a partir das árvores de documentos, processos, elementos e material básico, para a pequena empresa construtora possibilitou que materiais, serviços e fornecedores fossem relacionados. Partiu-se de um exemplo real baseado nos documentos da qualidade, levantados junto à empresa estudada.

\section{Conclusões}

Este trabalho consistiu na elaboração de uma proposta de estrutura para organização do conhecimento baseada nos documentos da qualidade, contemplando, assim, o objetivo apresentado.

Usando a classificação facetada, o conhecimento sobre os materiais e serviços utilizados pela empresa foi registrado e depois organizado em classes, segundo suas similaridades. Para isso foi necessária a discussão de termos e conceitos que melhor atendessem ao propósito da classificação. Optou-se por analisar termos e conceitos junto aos profissionais da construção civil com experiência em suas áreas. Eles podem ser considerados como especialistas e, dessa forma, têm condições de realizar uma análise mais abrangente da temática apresentada.

Um exemplo parcial da tabela de elementos da construção pode ser vista no Quadro 8, enquanto um exemplo de aplicação para o caso porta pode ser encontrado na Figura 2 e no Quadro 10. A representação completa da estrutura elaborada (árvore) com as respecticas tabelas de classificação pode ser encontrada em Cintra (2005).

A estrutura proposta pode assim ser considerada como uma estrutura genérica e que deverá ser adaptada pela empresa interessada em aplicá-la. A ênfase do trabalho está na montagem da estrutura em si, com o estabelecimento dos termos e conceitos relacionados a essa área do conhecimento. A proposta ora apresentada busca contribuir para a reorganização do conhecimento que se encontra disperso nas diversas áreas que se 
relacionam com a gestão da construção, particularmente no que se refere aos materiais e serviços envolvidos no processo da construção. Isso pode ser atribuído à existência de somente um documento (gráfico ou tabela) com a listagem dos documentos da qualidade e as relações entre eles e com o processo de construção.

\section{Referências}

AMORIM, S. R. L.; CHERIAF, M. Sistema de Indexação e Recuperação de Informação em Construção Baseado em Ontologia. In: ENCONTRO DE TECNOLOGIA DE INFORMAÇÃO E COMUNICAÇÃO NA CONSTRUÇÃO CIVIL, 3., 2007, Porto Alegre. Anais... Porto Alegre: ANTAC, 2007. 1 CDROM.

AMORIM, S. R. R.; PEIXOTO, L. A. CDCON: classificação e terminologia para a construção. In: BONIN, L. C.; AMORIM, S. R. L. (Org.). Coletânea Habitare: inovação tecnológica na construção habitacional. Porto Alegre: ANTAC, 2006. cap. 8, p. 189-219.

ASSOCIAÇÃO BRASILEIRA DE NORMAS TÉCNICAS. NBR 8037: porta de madeira de edificação. Rio de Janeiro, 1983.

\section{ASSOCIAÇÃO BRASILEIRA DE NORMAS} TÉCNICAS. NBR 8798: execução e controle de obras em alvenaria estrutural de blocos vazados de concreto. Rio de Janeiro, 1985.

\section{ASSOCIAÇÃO BRASILEIRA DE NORMAS \\ TÉCNICAS. NBR 10820: caixilho para \\ edificação: janela. Rio de Janeiro, 1989.}

\section{ASSOCIAÇÃO BRASILEIRA DE NORMAS} TÉCNICAS. NBR 10837: cálculo de alvenaria estrutural de blocos vazados de concreto. Rio de Janeiro, 1989.

\section{ASSOCIAÇÃO BRASILEIRA DE NORMAS} TÉCNICAS. NBR 10839: execução de obras de arte especiais em concreto armado e concreto protendido. Rio de Janeiro, 1989.

\section{ASSOCIAÇÃO BRASILEIRA DE NORMAS} TÉCNICAS. NBR 13531: elaboração de projetos de edificações: atividades técnicas. Rio de Janeiro, 1995.

ASSOCIAÇÃO BRASILEIRA DE NORMAS TÉCNICAS. NBR 6122: projeto e execução de fundações. Rio de Janeiro, 1996.
ASSOCIAÇÃO BRASILEIRA DE NORMAS TÉCNICAS. NBR 14037: manual de operação, uso e manutenção das edificações: conteúdo e recomendações para elaboração e apresentação. Rio de Janeiro, 1998.

\section{ASSOCIAÇÃO BRASILEIRA DE NORMAS} TÉCNICAS. NBR 7880: grade de tomada d'água para instalação hidráulica: terminologia. Rio de Janeiro, 2001.

\section{ASSOCIAÇÃO NACIONAL DE TECNOLOGIA DO AMBIENTE CONSTRUÍDO. Plano Estratégico para Ciência, Tecnologia e Inovação na Área de Tecnologia do Ambiente Construído com ênfase na Construção Habitacional. Disponível em: <http://www.mct.gov.br/Temas/Desenv/ECIB/com pleto.pdf $>$. Acesso em: 15 maio 2002.}

BAILEY, K. D. Typologies and Taxonomies: an introduction to classification techniques. Londres: Sage, 1994. 90 p.

BARBOSA, A. P. Classificações Facetadas. Ciência da Informação, Rio de Janeiro, v. 1, n. 2, p. 73-81, 1972.

\section{CAMPOS, M. L. de A. A Organização de} Unidades do Conhecimento em

Hiperdocumentos: o modelo conceitual como um espaço comunicacional para a realização da autoria. 2001. 186 f. Tese (Doutorado em Ciência da Informação) - Escola de Comunicação, Universidade Federal do Rio de Janeiro, Rio de Janeiro, 2001.

CDCON. O Projeto CDCON: desenvolvimento de terminologia e codificação de materiais e serviços para construção. Rio de Janeiro: [s.n.], 2003. 56 p.

CEFET. Dicionário da Construção. Disponível em: <http://www.cefet-se.com>. Acesso em: 15 maio 2004.

CHANDRASEKARAN, B.; JOSEPHSON, J. R.; BENJAMINS, V. R. What Are Ontologies, and Why Do We Need Them? IEEE Intelligent Systems \& Their Applications, v. 14, n. 1, p. 2026, jan./feb. 1999. Disponível em: <http://funnynoodle.com/soonho/meeting/021703/ chandra99.pdf>. Acesso em: 27 mar. 2004.

CINTRA, M.A.H. Uma proposta de estrutura para organização do conhecimento na pequena empresa de edificações. 2005. 176 f. Tese (Doutorado em Engenharia de Pordução) - COPPE, Universidade Federal do Rio de Janeiro, Rio de Janeiro, 2005. 
DRUCKER, P. F. Post-Capitalist Society. Nova York: Butterwoeth Heineman, 1993.

E-CIVIL. Dicionário on-line. Disponível em: $<$ http://www.ecivilnet.com/dicionario/>. Acesso em: 20 maio 2004.

GONÇAVES, R. F. et al. Um Modelo em UML para a Representação Sistêmica de Projetos em AEC. In: ENCONTRO DE TECNOLOGIA DE INFORMAÇÃO E COMUNICAÇÃO NA CONSTRUÇÃO CIVIL, 3., 2007, Porto Alegre. Anais... Porto Alegre: ANTAC, 2007. 1 CDROM.

INTERNATIONAL ORGANIZATION FOR STANDARDIZATION. ISO/DIS 12006-2: organization of information about construction works, part 2: framework for object-oriented information exchange. Genebra, 1998.

PROJECT MANAGEMENT INSTITUTE. PMBOK: project management body of knowledge. Tradução de PMIMG. Belo Horizonte: Project Management Institute, 2000.

RABELO, P. F. R.; AMORIM, S. R. L. ONTOARQ: ontologia para arquitetura, engenharia e construção: visualização e gerenciamento na web. In: ENCONTRO DE TECNOLOGIA DE INFORMAÇÃO E COMUNICAÇÃO NA CONSTRUÇÃO CIVIL, 3., 2007, Porto Alegre. Anais... Porto Alegre: Antac, 2007.

\section{RANGANATHAN, S. R. Phelogema Library} Classification. Bombaim: Asis Publishing House, 1967.

ROMANO, F. V. Modelo de Referência para o Gerenciamento do Processo de Projeto Integrado de Edificações. 2003. Tese (Doutorado em Engenharia de Produção) - Programa de PósGraduação em Engenharia de Produção, Universidade Federal de Santa Catarina, Florianópolis, 2003.
SANTOS, D. R. Padronização de Documentação de Projeto: contribuição para a modelagem do processo de projeto de edificações. 2004.

Dissertação (Mestrado em Engenharia Civil) Programa de Pós-Graduação em Engenharia Civil, Universidade Federal Fluminense, Niterói, RJ, 2004.

SCHIMDT, W. L. Microtesauro Engenharia Civil. Brasília: CNI/SENAI, 2000.

SECRETARIA DE ESTADO DA ADMINSTRAÇÃO E PATRIMÔNIO. Manual de Obras Públicas: edificações: práticas da SEAP. Brasília, 2001.

STEWART, T. A. Capital Intelectual. 7. ed. Rio de Janeiro: Campus, 1998. 237 p.

TCPO 2000. Tabelas de Composição de Preços para Orçamentos. São Paulo: Pini, 1999.

TRISTÃO, A. M. D. et al. Sistema de Classificação Facetada: instrumento para organização da informação sobre cerâmica para revestimento. Informação e Sociedade: estudos, João Pessoa, v. 14, n. 2, p. 109-136, jul./dez. 2004.

YAZIGI, W. A Técnica de Edificar. São Paulo: Pini, 1998. 93 p.

\section{Agradecimentos}

À CAPES - Fundação de Aperfeiçoamento de Pessoal de Nível Superior, pelo apoio concedido. 